\title{
Soil probiotic utilizes plant and pollinator transport for territorial expansion
}

Da-Ran Kim ${ }^{1}$, Gyeongjun $\mathrm{Cho}^{2}$, Chang-Wook Jeon ${ }^{2}$, David M. Weller ${ }^{3}$, Linda S.

Thomashow ${ }^{3}$, Timothy C. Paulitz ${ }^{3}$, Youn-Sig Kwak ${ }^{1,2, *}$

${ }^{1}$ Department of Plant Medicine and Institute of Agriculture and Life Science, Gyeongsang National University, Jinju 52828, Republic of Korea

${ }^{2}$ Division of Applied Life Science (BK21Plus) and Research Institute of Life Science, Gyeongsang National University, Jinju 52828, Republic of Korea

${ }^{3}$ US Department of Agriculture, Agricultural Research Service, Wheat Health, Genetics, and Quality Research Unit, Pullman, WA, USA 99164-6430

*Correspondence: kwak@gnu.ac.kr 


\begin{abstract}
Microbe-plant interactions are linked with the core microbiota, and both the plant and the microbial partners depend on one other to thrive in nature. However, why and how the below-ground core microbiota become established aboveground is poorly understood. We tracked the movement of a probiotic Streptomyces endophyte throughout a managed strawberry ecosystem. Probiotics in the rhizosphere and anthosphere were genetically identical, yet these niches were segregated in space and time. The probiotic in the rhizosphere moved upward via the vascular bundle, relocated to aboveground plant parts, and protected against Botrytis cinerea. It also moved from flowers to roots, and among flowers via pollinators that were protected against pollinator pathogens. Our results reveal a solid evidence in tripartite interaction with Streptomyces exploiting plant and pollinator partners.
\end{abstract}

Keywords: Core microbiota, Ecosphere, Streptomyces, Strawberry, Three kingdom partnership 


\section{Introduction}

Microbes colonize both the surface and the interior of plants in highly adapted communities essential to the growth, development and health of their hosts ${ }^{1,2}$. The microbial consortia differ in composition between above- and below-ground plant parts depending on the chemical, physical and environmental characteristics of the habitat ${ }^{3,4}$. Collectively, the microbes encode a second genome that expands the physiological function of the host by producing growth hormones, fixing nitrogen, mobilizing nutrients, inducing resistance mechanisms and defending against biotic and abiotic stresses ${ }^{5}$. The holobiont concept ${ }^{1,6}$ recognizes these unique relationships as evolutionary units ${ }^{7-9}$ with capabilities that exceed those of either partner alone ${ }^{10}$. Because they contribute to the well-being of the host, at least some of the associated microbes also can be considered plant probiotics, a term coined by Haas and $\mathrm{Keel}^{11}$ and explored in the context of crop productivity $^{12,13}$. Plant-associated microbial consortia differ according to the tissues they inhabit, and the selection, assembly and interactions of core probiotic agents with the host and other members of the microbial community in which they reside have only recently begun to be dissected ${ }^{14,15}$. The soil is an important source of much of the microflora found in both the rhizosphere and phyllosphere ${ }^{16,17}$. Flowers are essential for the biological success of most plants, yet flowers are the plant parts most vulnerable to biotic and abiotic stresses. Microbial communities of this ephemeral habitat remain poorly understood, and the interactions among beneficial and deleterious microbes that colonize flowers are especially elusive.

Plants rely on members of their microbiota to provide the first line of defense against pathogen attack ${ }^{18-20}$, but whether or how beneficial agents travel within or among plants is less clear. In this research, we used a managed strawberry ecosystem to trace a 
plant-probiotic partnership that has expanded to include a pollinator in its interactions. The core probiotic, an antibiotic-producing strain of Streptomyces, moves within the vascular system of the plant from the roots to the anthosphere and then is carried to other plants by pollinator bees. The probiotic defends the plant against attack by the gray mold pathogen Botrytis cinerea and the bees against insect pathogens. Using the plant and the pollinator transportation systems, Streptomyces benefits by effectively expanding its territory.

\section{Results}

\section{Gray mold disease incidence and microbial assemblages of flowers and pollen}

From November, 2013 to March, 2014 we collected samples at two-week intervals from strawberry (cv. Meahyang) cultivated in high-bed greenhouses in Jinju, Republic of Korea (Supplementary Fig 1a-f). Sequence analyses of bacterial DNA from flowers and pollen samples (Supplementary Table 1,2), identified operational taxonomic unit (OTU) numbers ranging from 10 to 30 for flower and from 14 to 25 for pollen samples, respectively. Thus, regardless of the origin and sampling time, the communities were relatively simple (Fig. 1a,b). Principal coordinates analysis (PCoA) indicated that in both the pollinated flower and the pollen samples, communities shifted over time and differentiated into high diversity (HD, samples 1-7) and low diversity (LD, samples 8-13) groups over the course of the season (Fig. 1c,d). Comparing the OTUs in the HD and LD groups from flowers, Proteobacteria were the most abundant, followed by Actinobacteria. 
Streptomyces globisporus NRRL B-3872 (accession number, EF178686) was the most frequently detected (Supplementary Table 3). Abundant bacteria in the pollen HD group included mainly Proteobacteria, with fewer Actinobacteria and Firmicutes (Supplementary Table 4). Among the combined flower and pollen samples, OTUs of Streptomycetaceae were consistently represented only in the HD group (Supplementary Table 5). Actinobacteria comprised $44.9 \%$ of the core bacteria in flowers and $43.8 \%$ in pollen (Supplementary Table 6). As previous reports have hypothesized that the microbial community can benefit plant health ${ }^{21,22}$, we next established the relationship between the microbiota and the occurrence of gray mold disease and spore density of the pathogen Botrytis cinerea in air during strawberry growth (Supplementary Fig. 2a-e). Gray mold is the most important disease of many greenhouse-grown crops including strawberries. Disease incidence increased dramatically from flower sample 9 and peaked at sample 11, when $33 \%$ of all berries were damaged (Supplementary Fig. 2e). Comparing the pattern of disease incidence with that of the bacterial community structure throughout the growing season revealed that gray mold occurrence increased rapidly at the $8^{\text {th }}$ sampling when the bacterial community shifted from the HD to the LD configuration lacking the S. globisporus NRRL B-3872. The decline in the Streptomyces OTU population beginning at sample 8 correlated with a sharp increase in symptoms of gray mold disease (Fig. 1e). A common OTU in the HD group of both flower (Fig. 1f) and pollen (Fig. 1g) samples was identified as $S$. globisporus NRRL B-3872 and prompted the hypothesis that if the bacteria contribute to the maintenance of plant health, there would be specific beneficial probiotic(s) present. 


\section{Selection and identification of core bacterial isolates}

A total of 887 and 324 isolates was recovered from flowers and pollen, respectively. After antifungal screening in vitro, 44 isolates from flowers (Supplementary Table 7) and 22 from pollen (Supplementary Table 8) were selected as putative probiotic strains. Among these, Streptomyces species were targeted based on the results of sequencing, bacterial community shifts and gray mold disease incidence. Seven Streptomyces strains from flowers and 9 from pollen (Supplementary Table 9) were identified as $S$. badius, $S$. globisporus or $S$. griseus by sequencing $16 \mathrm{~S}$ rRNA (99\% similarity). Multigene phylogenies of 16S rRNA, gyrB and recA genes of strains SP6C4 and SF7B6 showed these bacteria to be related most closely to $S$. griseus (Fig. 2a). Recently, S. badius, $S$. griseus, and $S$. globisporus have been categorized as part of the "S. griseus group" ${ }^{23}$. Strains SP6C4 (isolated from pollen in sample 6) and SF7B6 (isolated from flowers in sample 7) were indistinguishable from each other, although they were recovered from different sources and sampling time points to minimize the probability of recovering the same clone twice. Comparison of the two genome sequences by Average Nucleotide Identity (ANI) revealed $99.99 \%$ sequence identity and unexpectedly, both shared $99.99 \%$ genomic sequence identity with strain S. griseus S4-7 (Fig. 2b), the well-characterized probiotic isolated in 2012 that protects strawberry against Fusarium wilt disease ${ }^{19}$. All three strains also shared the same sequence maps by the Web Artemis Comparison Tool (ACT) (Fig. 2c). S. globisporus C1027 showed 96.1\% genomic sequence similarity as the closest related reference bacterium among the three strains (Fig. 2d). Bacteria with greater than $94 \%$ similarity in ANI are considered to be the same species ${ }^{24}$. Accordingly, the three strains were re-classified as S. globisporus S4-7, SF7B6, and SP6C4. 


\section{S. globisporus SP6C4 movement in planta}

Identity among the three strains also suggested that the strain can colonize flowers and even pollen attached to bee bodies, leading us to hypothesize that it establishes in the rhizosphere, moves internally as an endophyte to the phyllosphere, and can transfer to pollinators. This model is consistent with a probiotic-driven relationship in an ecosystem that includes both plants and insects. The hypothesis was tested by dipping roots of strawberry into a suspension of strain SP6C4 $\left(10^{6} \mathrm{cfu} / \mathrm{mL}\right)$ or by dropping $100 \mu \mathrm{L}$ of the bacterial culture by pipette onto the flower stamens and carpels. Both treatments consisted of two independent experiments, one in which the introduced strain carried the strain specific marker gene $\operatorname{lan} M^{25}$ and the other in which it was labeled with mCherry. Five days after root inoculation, the bacteria were detected in the endosphere of root tissue (Fig. 3a,b). By 10 days, the root and stem showed mCherry fluorescence in the cambium near the xylem in vesicular bundles (Fig. 3c), tested positive for lanM, and maintained population sizes of up to $10^{6}$ copies/g of tissue until 20 days. At 30 days, mCherry fluorescence was greatly reduced in the xylem and endodermis of the stem (Fig. 3d).

Flowers inoculated with SP6C4 retained a population size of at least $10^{5} \mathrm{lanM}$ copy/g of tissue until 15 days (Fig. 3e). At 10 days, the bacteria were detected at up to $10^{5}$ lanM copy/g of tissue in stem and crown parts, where high population densities were maintained for up to 30 days. The bacteria were initially detected in the rhizosphere at 15 days ( $10^{5}$ lanM copy/g of tissue) and remained detectable by qPCR for up to 30 days (Fig. 3e). The mCherry-labeled strain was first observed on the stigma and pistil 5 days after inoculation of the stamens and pistils (Fig. 3f,h). At 15 days, fluorescence was observed 
along the filaments of both stamens and pistils (Fig. 3g,i). In cross sections just above the crown, middle part of the stem and the petiole, fluorescence was detected from 10 days (Fig. 3j) up to 30 days (Fig. 3k). mCherry fluorescence was observed in the xylem and endodermis in vascular bundles of root tissue. These results provide incontrovertible evidence that the probiotic can translocate endophytically from the soil to above-ground plant tissues, and from the phyllosphere to the rhizosphere.

Furthermore, to evaluate movement from plant to plant by a pollinator, suspensions of a hygromycin-marked strain $\left(10^{6} \mathrm{cfu} / \mathrm{mL}\right)$ were introduced on the surface of flower stamens and carpels (Fig. 4a). Five days later, surface populations on detached flowers remained at up to $10^{7} \mathrm{cfu} / \mathrm{g}$ of flowers, consistent with successful colonization of the flower surface. Subsequently, strain SP6C4 was detected at $10^{5} \mathrm{cfu} / \mathrm{g}$ of honeybee body and at $10^{6} \mathrm{cfu} / \mathrm{g}$ on non-inoculated flowers visited by the bees (Fig. 4b). These findings clearly indicate that the strain can immigrate from one plant to another via transport by the pollinator.

\section{Gray mold disease suppression by core bacteria}

We next addressed why the plant and the honeybees act as vehicles of transport of the strain. In this experiment, plants in one greenhouse served as an untreated control and those in a separate greenhouse were treated from November 2016 to February 2017. The treated greenhouse also had an area enclosed in netting to block honeybee access (Supplementary Fig. 3c,d). SP6C4 was applied to plants via a honeybee delivery system set up in front of the hive (Supplementary Fig. 3b) during the time from flower samples 
4 to 6 . In the untreated greenhouse, symptoms of gray mold disease first appeared at flower sampling 3 and by sampling 6, 41\% of the flowers were diseased (Fig. 4d). In the netted area, a similar level of disease incidence was observed (Fig. 4e). In contrast, disease incidence in the SP6C4-treated greenhouse remained at 10\% through sampling 6 (Fig. 4f). In the treated greenhouse, strain SP6C4 was present at a population density $10^{5}$ lanM copy/g of flower immediately after introduction by honeybees at the time of sample 4, and the population reached $10^{6} \operatorname{lan} M$ copy/g at the time of flower sample 6 (Supplementary Fig. 4c). In the untreated greenhouse and the netted area in the treated greenhouse, the population of the strain remained at levels undetected by qPCR (Supplementary Fig. 4a,b). Sequencing results (Supplementary Tables 10,11) revealed that Actinobacteria comprised $15 \%$ of the microbial community on flowers that had been visited by honeybees by the time of sampling 6 (Fig. 4f and Supplementary Fig. 4c), whereas less than $2 \%$ of Actinobacteria were detected on flowers in the untreated greenhouse and in the blocked area (Fig. 4d,e and Supplementary Fig. 4a,b). Concurrent with the change in microbial diversity on flowers with the SP6C4 treatment, the incidence of gray mold disease was significantly reduced as compared to that in the untreated greenhouse and in the blocked area of the treated greenhouse.

\section{Protecting the pollinator against entomopathogens}

The bees also benefited from the interaction because strain SP6C4 inhibited the entomopathogenic bacteria Paenibacillus larvae and Serratia marcescens (Supplementary Fig. 5c). Caged bees fed pollen containing no bacteria or only strain SP6C4 for 5 days had 30\% mortality (Fig. 4c), whereas those fed pollen inoculated with 
the bee pathogens had 70\% ( $P$. larvae) and 90\% (S. marcescens) mortality, respectively. Survival was approximately 50\% when SP6C4 was mixed with the pathogens, indicating that the SP6C4 reduced mortality even when bees were fed entomopathogens. These findings demonstrated that the probiotic was capable of providing disease-suppressive activity to both the plant and the insect.

\section{Characterization of antibiotic functional genes in SP6C4}

As a final step, we used antiSMASH ${ }^{26}$ to predict secondary metabolite gene clusters in SP6C4. Among 15 predicted antibiotic-related genes that were divided into linked nonribosomal protein synthase-polyketide synthase, polyketide synthase, ribosomal protein synthase-lanthipepetide and thiopeptide groups (Supplementary Table 12). Analysis by qRT-PCR showed that members of the antibiotic-related genes were reliably expressed except for cluster 13 (Supplementary Fig. 5a). Mutants in the remaining 14 clusters did not differ in growth and sporulation from the wild-type strains. However, mutants in lantipeptide clusters 17 (tsrD) and 20 (lanM) were significantly less inhibitory to the gray mold pathogen (Supplementary Fig. 5b), and a mutant in cluster 16, encoding a lassopeptide, was less active against the entomopathogenic bacteria (Supplementary Fig. 5c). The findings support the hypothesis that the core probiotic carries an arsenal of antibiotics needed to provide dual protection to the plant and the pollinator.

\section{Discussion}


Beneficial plant-microbe interactions in the rhizosphere have been recognized for well over a century ${ }^{27}$, but appreciation of these associations in the context of the holobiont concept $\mathrm{t}^{1,28}$ is much more recent. Similarly, whereas plant-microbe relationships have often been characterized in relation to disease, it has become apparent in the past few years that the outcome of such relationships is driven in part by rhizosphere mutualists either supportive or antagonistic to pathogens ${ }^{4,21,29}$. The recruitment and maintenance over time of such specific, environmentally-selected "core" mutualists supportive of host health is at the heart of the holobiont concept ${ }^{14,29,30}$, and the functions mediated by these strains can explain in part the unique community structure of different plant species ${ }^{4}$ or even interconnected plant parts. In our study, the absence of the core Streptomyces antagonist coincident with lack of suppression of the Botrytis pathogen during LD sampling periods, and its dominance in flowers and pollen during HD sampling periods, provides strong support for the suggestion of Durán et al. ${ }^{21}$ that individual members of the microbiota can have a central role in the health of the holobiont.

We previously reported that a strain of Streptomyces from disease suppressive field soil became a dominant member of the bacterial population and protected strawberry against Fusarium oxysporum f. sp. fragariae during mono-culture ${ }^{19}$. Building on these results, we have shown that the genetically identical strain S. globisporus SP6C4 from the rhizosphere of greenhouse-grown plants enters the endosphere and migrates upward to deliver protection against an air-borne foliar pathogen. Only a fraction of the rhizosphere community has the capacity to colonize the plant endosphere in a process actively controlled by the host ${ }^{3,31}$, but once established, these bacteria can travel via the xylem to the stem, leaves and flowers ${ }^{32}$. Our evidence that SP6C4 is transferred from the 
rhizosphere to pollinators directly via the endosphere provides insight into a novel route that offers adapted microflora not only the potential for territorial expansion via air movement, bioaerosols and contact with other foliar insects ${ }^{2,33}$, but also the most efficient means of translocation to other hosts that subsequently benefit as the Streptomycetes move systemically from the stigma to the rhizosphere. As the vector in this process, the pollinator gains protection against common entomopathogens but the flower serves as the hub in a unique tripartite system that benefits all three partners. While flowers typically harbor less diversity and fewer inhabitants than rhizosphere or phyllosphere communities $^{16,34}$, our results (Fig. 1a), may provide evidence that selected members of the anthosphere may have a greater role in the plant ecosphere that has previously been recognized.

To fully understand the persistence of microorganisms in the environment requires detailed knowledge of their individual capabilities and needs as well as recognition of the give-and-take involved in their interactions with other members of the ecosystem. The relationships among the microbe, the plant, and the insect in this study exemplify Commoner's laws of ecology ${ }^{35}$; that "everything is connected to everything else" within an ecosphere, with members interdependent such that "there is no such thing as a free lunch." For every profit there is a cost, with all duties eventually paid to other members of the system. In our study, the plant served as a host in the space inhabited by the three partners, the insect provided plant-to-plant transportation and the probiotic maintained the partnership by producing antibiotics that benefited both the plant and the insect. From an ecological perspective, when the soil, the plant and the pollinators are considered as separate environments inhabited by microorganisms, the Streptomyces in our system 
transformed the three into a symbiotic continuum with the plants as the source of space and nutrients. A better understanding the relationships within such mutualistic phytobiomes will facilitate the use of the native microbiota and specific introduced agents to defend against biotic and abiotic stresses, thus more sustainably protecting the world's food supply.

\section{Methods}

\section{Sampling and pyrosequencing of flowers and pollen during strawberry growth}

Strawberry (cv. Meahyang) was cultivated in high-bed greenhouses in Jinju, Republic of Korea. Samples of flowers and honeybee pollen were collected over two seasons from November 2013 to March 2014 and from November 2016 to February 2017. At each sampling time, flowers were collected every two weeks from both the edges and the central rows in the greenhouse to form replicates (Supplementary Fig.1a-d). Each sampled plot contained 100 strawberry plants, from among which 10 - 15 flowers were randomly collected, comprising a single replicate. Three samples were collected in each high-bed row, and the three samples from a row were placed in different $50-\mathrm{mL}$ Falcon tubes, yielding nine tubes per greenhouse. Two honeybee hives were used for each greenhouse, and a pollen collector was attached to each hive for collection of pollen samples at two-week intervals during strawberry growth (Supplementary Fig. 1d-f). Flower and pollen samples were stored in a portable refrigerator after collection and transported to the laboratory within $30 \mathrm{~min}$, where each sample was weighed and adjusted to $1 \mathrm{~g}$. For flower samples, $30 \mathrm{~mL}$ of $1 \mathrm{X}$ PBS buffer (10 X PBS: $8 \mathrm{~g}$ of NaCl, $0.2 \mathrm{~g}$ of 
$\mathrm{KCl}, 1.44 \mathrm{~g}$ of $\mathrm{Na}_{2} \mathrm{HPO}_{4}, 0.24 \mathrm{~g}$ of $\mathrm{KH}_{2} \mathrm{PO}_{4}$, adjusted to a $\mathrm{pH}$ of 7.4 and a final volume of $1 \mathrm{~L}$ ) was added. Pollen samples received $20 \mathrm{~mL}$ of 1 X PBS buffer. Then the sample tubes were sonicated at $35 \mathrm{kHz}\left(20 \mathrm{~min}, 4^{\circ} \mathrm{C}\right)$ to detach microbes and $3 \mathrm{~mL}$ of the mixture was centrifuged $\left(12,470 \mathrm{xg}, 10 \mathrm{~min}, 4^{\circ} \mathrm{C}\right)$. The supernatant solution was discarded and total DNA in the pellet was purified using a genomic DNA isolation kit (Solgent, Daejeon, Korea). For each sampling time, DNA was extracted individually from nine flower samples and two pollen samples, and then the DNA of the flower or pollen samples was pooled (20 $\mu \mathrm{L}$ from each sample, DNA concentrations ranging from $180-200 \mathrm{ng} / \mu \mathrm{L}$ ). To check the quality of the DNA samples and to determine the composition of the communities, 16S rRNA PCR reactions were conducted. Total DNA (100 ng) was reacted with the primer pair $27 \mathrm{mF} \quad\left(5^{\prime}\right.$-gagtttgatcmtggctcag-3') and $518 \mathrm{R} \quad\left(5^{\prime}\right.$ wttaccgcggetgctgg-3') to amplify the V1 - V3 region. Pyrosequencing was performed using 454 GS-FLX titanium system with a Roche Genome Sequencer (GS) FLX software (v 3.0). Samples were placed on a PicoTiter plate to obtain raw signals of sequences, and after being filtered to remove background noise the signals were sorted by barcode tag sequences. Sequencing reads were checked both for nucleotide quality scores (average Phred score $>20)$ and read lengths $(>300 \mathrm{bp})$. Rarefaction was calculated with iNEXT (version 2.0.12) in R (version 3.4.4.) (Supplementary Fig. 6a,b). Operational taxonomic units (OTUs) were established using CD-HIT-OTU clusters, rRNA tags, and Mothur (version 1.33.0). Nucleotide sequence similarity of $16 \mathrm{~S}$ rRNA sequences was followed at similarity levels: phylum, $>75 \%$; class, $>80 \%$; order, $>85 \%$; family, $>90 \%$; genus, $>94 \%$ and species, $>97 \%$. The rarefaction curves, microbial communities, top OTUs and Principal Coordinates Analyses (PCoA) were conducted with QIIME. GenBank accession numbers are presented in Table S13. 


\section{Botrytis cinerea spore density and incidence of gray mold}

A spore sampler (UCK Bio-Culture TMU Pump, USA) and Botrytis Spore Trap Medium (BSTM: glucose $2 \mathrm{~g}, \mathrm{NaNO}_{3} 0.1 \mathrm{~g}, \mathrm{~K}_{2} \mathrm{HPO}_{2} 0.1 \mathrm{~g}, \mathrm{MgSO}_{4} \cdot 7 \mathrm{H}_{2} \mathrm{O} 0.2 \mathrm{~g}, \mathrm{KCl} 0.1$ g, chloramphenicol $0.2 \mathrm{~g}$, pentachloronitrobenzene $0.02 \mathrm{~g}, 80 \%$ manganese ethylene bisdithiocarbamate $0.02 \mathrm{~g}, 12 \%$ fenarimol $0.1 \mathrm{~mL}$, tannic acid $5 \mathrm{~g}$, agar $20 \mathrm{~g}$ per $1 \mathrm{~L}, \mathrm{pH}$ 4.5) were used to trap conidia of the pathogen ${ }^{37}$. The BSTM plates were inserted into the sampler and air was aspirated over the plates (240 L, 2 min), which were then sealed with Parafilm and incubated at $28^{\circ} \mathrm{C}$ for 5 days. Colony numbers of the pathogen were counted and spore densities were calculated and expressed in log colony forming units (cfu)/L of air.

Gray mold disease incidence and spores of the pathogen were collected at two-week intervals in the greenhouses. The greenhouse was divided into nine blocks, each $5 \mathrm{~m}$ long and containing about 100 strawberry plants. Disease symptoms appeared as brown spots on petals, leaves and fruits, with masses of gray or brownish spores eventually produced on infected stems, or as mummified berries (Supplementary Fig. 2a-d). Differences in disease incidences among the treatments were analyzed by ANOVA followed by the Turkey HSD $(P=0.05)$ for mean separation.

\section{Isolation and antifungal activity of Streptomyces strains from flowers and pollen}

Bacteria isolated from flowers and pollen in 1X PBS solution were diluted $10^{-8}$-fold in sterile water, plated in triplicate onto tryptic soy agar (TSA: tryptic soy broth (Difco) $30 \mathrm{~g}$, agar 20 g per $1 \mathrm{~L}$ ), cultured at $28^{\circ} \mathrm{C}$ for 10 days, and CFUs were calculated based 
on the number of colonies in the terminal dilution plates. Each colony was inoculated into $100 \mu \mathrm{L}$ of tryptic soy broth (TSB) in a 96-well plate, which was shaken at $28^{\circ} \mathrm{C}$ for 2 days. Then, $100 \mu \mathrm{L}$ of $50 \%$ glycerol was mixed into the wells by pipetting and the plates were sealed with Platemax ${ }^{\circledR}$ pierceable aluminum sealing film (Axygen, United States) and stored at $-80^{\circ} \mathrm{C}$.

Antifungal Streptomyces isolates in the bacterial collections were detected by a threestep screening procedure. First, bacteria from the 96-well plates were replica-plated onto Omni-trays (Sigma-Aldrich, USA) of PDK medium (potato dextrose (Difco) $24 \mathrm{~g}$, peptone $10 \mathrm{~g}$, agar $20 \mathrm{~g}$ per $1 \mathrm{~L}$ ) and cultured at $28^{\circ} \mathrm{C}$ for 2 days. Then, 4-mm-diam.plugs of actively growing mycelia of $B$. cinerea were placed between the bacterial colonies. Second, colonies that inhibited fungal growth were suspended in sterile water, the concentration was adjusted to $10^{6} \mathrm{cfu} / \mathrm{mL}$, and $10 \mu \mathrm{L}$ was spotted onto PDK agar and streaked along a 3-cm-long line. Three days later, a 4-mm-plug of the fungus was placed at the center of the plate, $2 \mathrm{~cm}$ from the bacteria. Fungal inhibition was evaluated 5 days later. This screening was repeated with selected inhibitory isolates, with antifungal activity defined based on the distance between the pathogen and the antagonist after 5 days and denoted as - no inhibition; + (low inhibition), 0.1-0.5 cm; ++ (medium inhibition), $0.5-1 \mathrm{~cm} ;+++$ (strong inhibition), $1-1.5 \mathrm{~cm} ;++++$ (the highest inhibition), $>1.5 \mathrm{~cm}$.

\section{Entomopathogen inhibition in vitro}

A two-layer method was used to test for antibiotic activity against entomopathogenic bacteria ${ }^{38}$. Streptomyces strains were suspended to give $10^{6} \mathrm{cfu} / \mathrm{mL}$, and $10 \mu \mathrm{L}$ was inoculated onto a 0.8 -cm filter disk on PDK agar. Paenibacillus larvae 
and Serratia marcescens were cultured in PDK broth for 3 days at $28^{\circ} \mathrm{C}$, then a $5-\mathrm{mL}$ culture of each pathogen was mixed into $25 \mathrm{~mL}$ of pre-cooled $0.2 \%$ PDK agar and overlaid onto the plates. The plates were dried for $30 \mathrm{~min}$, incubated at $28^{\circ} \mathrm{C}$ for 5 days and antibacterial activity was indicated by the size of the inhibition zone around the disk. The entomopathogen growth inhibition assay was repeated 5 times as replications and ANOVA followed by Tukey's HSD $(P=0.05)$ was used for mean separation.

\section{Sequencing and prediction of secondary metabolites of the selected Streptomyces strains}

Two independent strains, SP6C4 and SF7B6, were grown in TSB amended with $20 \%$ sucrose, transferred to MS medium (soya flour, 20g; mannitol, $20 \mathrm{~g}$; agar, $20 \mathrm{~g}$ per $1 \mathrm{~L}$ water $)^{36}$ and cultured at $30^{\circ} \mathrm{C}$ for 7 days. Spores were collected into $1.5-\mathrm{mL}$ Eppendorf tubes and genomic DNA was extracted by using a CTAB lysozyme procedure ${ }^{39}$. DNA quality was determined with a NanoDrop 2000C spectrophotometer (Thermo, Denmark). For identification of the isolates, full-length16S rRNA, gyrB, and $\operatorname{rec} A$ genes were sequenced. PCR was performed with $1 \mu \mathrm{L}$ of DNA, $4 \mu \mathrm{L}$ of dNTPs $(2 \mathrm{mM}), 1 \mu \mathrm{L}$ of 10 pmol of each primer (Supplementary Table 14), $0.3 \mu \mathrm{L}$ of KOD FX Neo (1.0 unit/ $\mu \mathrm{L}$ ), $20 \mu \mathrm{L}$ of $2 \mathrm{X}$ PCR buffer, and sterile water to a final volume of $40 \mu \mathrm{L}$. The PCR program consisted of an initial denaturation at $98^{\circ} \mathrm{C}$ for $5 \mathrm{~min}, 30$ cycles at $98^{\circ} \mathrm{C}$ for $30 \mathrm{sec}, 55^{\circ} \mathrm{C}$ for $30 \mathrm{sec}, 72^{\circ} \mathrm{C}(2 \mathrm{~min}$ for $16 \mathrm{~S}$ RNA and $g y r B ; 1 \mathrm{~min}$ for $r e c A)$, and a final extension at $72^{\circ} \mathrm{C}$ for $10 \mathrm{~min}$. Amplicons were visualized in $1 \%$ agarose to confirm the size $(1.4-\mathrm{kb}$ for 16S rRNA, 1305-bp for $g y r B$, 913-bp for $r e c A$ ) and sequenced by the Sanger method at Solgent (Daejeon, Korea). Sequences were aligned using ClustalW (http://www.ebi.ac.uk/Tools/msa/clustalo/) ${ }^{40}$ and phylogenetic trees were created by 
MEGA 7 software with a neighbor-joining algorithm ${ }^{41}$.

\section{PacBio genome sequencing with Streptomyces strains}

Genomes were sequenced with the Pacific Biosciences RSII (PacBio, USA) single molecule real time (SMRT) system and non-hybrid hierarchical genome (HGAP version 2.3) pre-assembly Quiver (http://www.pacificbiosciences.com/devnet/). Whole genome alignment used the Web ACT program (Artemis Comparison Tool, Center for Bioinformatics). Circular genome mapping and analysis were conducted with BLAST Ring Image Generator (BRIG) v 0.95 (http://sourceforge.net/projects/brig/) ${ }^{42}$. RAST version 2.0 release 70 with genetic code option 11 and other automatic pipeline options and SEED-based prokaryotic genome public databases were employed to annotate ${ }^{43}$ the genomes. Secondary metabolism of bioactive compound biosynthetic gene clusters was predicted by antiSMASH (http://antismash.secondarymetabolites.org) version 3.0.5. Results were run with the cluster finder algorithm, a minimum cluster size CDS of 5, minimum cluster finder probability score of 0.6 , and automatic remaining options at the site.

\section{Colonization of flowers by Streptomyces and movement by pollinators}

To determine whether Streptomyces strains could be moved by pollinators between flowers, flowers were divided into three groups and covered by a plastic cage $(25 \times 25 \times 25 \mathrm{~cm})$. The first set of flowers received no bacterial treatment and was covered with a transparent plastic cap to prevent access by honeybees (Apis nearctica). The second set of flowers also received no bacteria but had no plastic cap, which allowed access to honeybees. Flowers in the third set were inoculated with $100 \mu \mathrm{L}\left(10^{6} \mathrm{cfu} / \mathrm{mL}\right)$ of a hygromycin-resistant derivative of strain SP6C4 suspended in $0.1 \%$ methylcellulose 
(MC), and the cups were not capped. Next, seven A. nearctica were released into the cage and flower samples were harvested 5 days later because when visited by bees, the flowers became withered after that time. The population density of SP6C4 on the bee bodies and the flowers of each treatment was determined. A one-gram sample of flowers or a single bee was placed in 50-mL Falcon tubes containing $30 \mathrm{~mL}$ (flower) and $20 \mathrm{~mL}$ (bee) of PBS buffer. Tubes were sonicated at $35 \mathrm{kHz}$ with cooling for $10 \mathrm{~min}$, the buffer solution was filtered with two layers of cheesecloth, and then serially diluted, vortexed, and spread onto PDK medium amended with $80 \mu \mathrm{g} / \mathrm{mL}$ hygromycin. The plates were incubated at $28^{\circ} \mathrm{C}$ for 5 days and population sizes were calculated for each sample. This experiment was conducted with three independent biological replications and all results were statistically analyzed by ANOVA.

\section{Bacterial movement evaluation by qPCR between the rhizosphere and the flower}

To observe bacterial movement from the rhizosphere to the phyllosphere, 45 day-old strawberry roots were dipped for 5 min into a culture of strain SP6C4 that had been grown in PDK broth amended with $0.1 \% \mathrm{MC}$ to a density of $10^{6} \mathrm{cfu} / \mathrm{mL}$. The inoculated plants were planted in plastic pots $(9 \mathrm{~cm}$ diam.) containing $450 \mathrm{~g}$ of sterilized commercial potting mix and the pot was covered with plastic wrap to prevent bacterial spread by watering or airflow and then incubated in a growth chamber $\left(16 \mathrm{~h} \mathrm{light,} 28^{\circ} \mathrm{C}\right.$, $45 \%$ relative humidity; $8 \mathrm{~h}$ of dark, $24^{\circ} \mathrm{C}, 45 \%$ relative humidity).

For movement from the flower to the rhizosphere, $100 \mu \mathrm{L}$ of a culture of SP6C4 grown to $10^{6} \mathrm{cfu} / \mathrm{mL}$ in PDK broth containing $0.1 \% \mathrm{MC}$ was dropped by pipette onto petals. Root- and flower-inoculated plants were harvested at $0,5,10,15,20,25$, and 30 
days after inoculation. At each sampling day, three plants were removed from the pots. Tissues (root, crown and stem) samples were cut into 2-cm-long pieces and placed in 50$\mathrm{mL}$ Falcon tubes. For surface sterilization, the pieces were washed in $70 \%$ ethanol, $1 \%$ $\mathrm{NaOCl}$ for $1 \mathrm{~min}$, and finally rinsed 5 times with sterile water. The sterilized plant pieces were transferred into new 50-mL Falcon tubes with PBS buffer $(30 \mathrm{~mL}$ for flower; $20 \mathrm{~mL}$ for stem, crown and root samples) and the pieces were sonicated at $35 \mathrm{kHz}$ with cooling for $30 \mathrm{~min}$. The sample pieces were dried on sterilized filter paper for $15 \mathrm{~min}$ in a fume hood. The dried samples (root, stem) were re-cut 0.8 -cm-long from each end to obtain the middle parts $(0.5$-cm-long). The pre-sterilized middle parts were homogenized in $1 \mathrm{~mL}$ PBS then sonicated at $35 \mathrm{kHz}$ with cooling for $10 \mathrm{~min}$. The pre-sterilized crown samples were cut into cubes $(0.5 \times 0.5 \times 0.5 \mathrm{~cm})$, then homogenized in $5 \mathrm{~mL}$ PBS. Flower samples followed the same sterilization process and dried flower pieces were homogenized in 500 $\mu \mathrm{L}$ PBS. Each sample (500 $\mu \mathrm{L}$ PBS) was mixed with an equal volume of CTAB and DNA was extracted. Strain movement was detected by qPCR with lanM as the strain-specific marker gene (Supplementary Table 15), which previously was verified as a S4-7 specific detection marker ${ }^{25}$. For the qPCR reaction, $100 \mathrm{ng}$ of DNA was used as template, with 25 $\mu \mathrm{L}$ of SYBR Green ${ }^{\circledR}$ TOYOBO master mix (QPK-201T, Japan), $1 \mu \mathrm{L}$ of each forward and reverse primer, and $16 \mu \mathrm{L}$ of HPLC grade $\mathrm{H}_{2} \mathrm{O}$. The PCR program included initial denaturation at $98^{\circ} \mathrm{C}$ for $1 \mathrm{~min}$, denaturation at $98^{\circ} \mathrm{C}$ for $30 \mathrm{sec}$, followed by annealing at $59^{\circ} \mathrm{C}$ for $30 \mathrm{sec}$, and elongation at $72^{\circ} \mathrm{C} 45 \mathrm{sec}$ for 40 cycles. qPCR was performed with CFX Connect ${ }^{\mathrm{TM}}$ Optics Module Real-Time PCR System (Bio-Rad, USA). The experiment was conducted with five biological replications and qPCR had 15 replications for each tissue and time point sample. 


\section{Fluorescent imaging of SP6C4 in planta}

To visualize bacterial movement, mCherry-fluorescence of SP6C4 and confocal microscopy were used; this experiment was independently performed from the qPCR detection experiment. The mCherry gene in pET21a(+)-HIStag-mCherry (Plasmid \#70719, Addgene, Cambridge, MA USA) was employed to generate a fluorescent derivative of strain SP6C4. The mCherry region was amplified with pBRrevBam-PacI (5'- ttaattaaggtgatgtcggcgatatagg-3') and the T7 terminator primer (5'gctagttattgctcagcgg-3') as an 807-bp fragment, ligated into pGEM-T easy vector (Promega, USA), and transformed into E. coli DH5 $\alpha$. Transformants were selected on LB agar and the plasmids were recovered with a Dokdo Mini-prep Kit (ELPIS-Biotech, Korea) and digested with XhoI and PacI. At the same time, pIJ10257 was cut with the same enzymes, and the digested plasmid and the mCherry fragments were purified from agarose gels and ligated together by T4 ligase. The construction was transformed into $E$. coli ET12567/puZ8002. Conjugation with SP6C4 was by the same procedure as in the mutagenesis protocol. After conjugation, colonies were selected on agar containing hygromycin $(80 \mu \mathrm{g} / \mathrm{mL})$ and by detection of a hygromycin resistance gene by PCR with primers hyg-det 3: 5'-tccgctgtgacacaagaatc-3' and hyg-det 5:5'-cggctcatcaccaggtagg-3'. Confocal microscopy was performed with a Zeiss LSM 510 laser scanning microscope (Zeiss, Germany). To confirm labeling with mCherry, plant tissues were prepared on sterilized coverslips inserted at a $45^{\circ}$ angle into MS medium inoculated with $50 \mu \mathrm{L}$ of a spore stock of the fluorescent SP6C4 strain and grown for 4 days at $30^{\circ} \mathrm{C}$. Fluorescence was detected at $488 \mathrm{~nm}$ excitation and 530-560 nm detection channels, respectively. 
For visualization of movement from rhizosphere to phyllosphere tissue, the plant was treated with the mCherry-labeled strain and harvested as described above in the movement assay. To treat the anthosphere, a strawberry plant with a flower was planted in a plastic pot (90 mm diam.), and $100 \mu \mathrm{L}$ of the diluted bacterial solution $\left(10^{6} \mathrm{cfu} / \mathrm{ml}\right)$ in $0.1 \% \mathrm{MC}$ was applied to the petal of flower. Plants were covered with plastic wrap to prevent contamination. Rhizosphere, root and stem samples were collected at $0,5,10,15$, 20, 25, and 30 days after inoculation. Anthosphere samples were collected at intervals of 5 days for 15 days, after which the flowers had withered and become detached. Samples were cut into cross sections using scissors, and the samples were fixed with $4 \%$ paraformaldehyde. All samples were prepared for microscopic observation with the ClearSee protocol $^{44}$.

\section{SP6C4 treatment to reduce strawberry gray mold in the greenhouse}

To test whether the selected strain reduces gray mold disease incidence on strawberry, strain SP6C4 was introduced into the greenhouse via an attachment to the honeybee hives. Bacteria were grown with shaking in PDK broth at $28^{\circ} \mathrm{C}$ for 7 days, diluted to $10^{7} \mathrm{cfu} / \mathrm{mL}$ and PEG and skim milk were added to give final concentrations of $12.5 \%$ and $3 \%$, respectively. The mixture was applied by pouring into a delivery device attached at the front of the hive (Supplementary Fig. 3b). A second greenhouse served as a control and as an additional untreated control, three random groups of seedlings were covered with a 3-m-long net to prevent honeybee access in the treated greenhouse (Supplementary Fig. 3c,d). Disease incidence throughout the growing season was performed as described above and nine replications were analyzed by ANOVA followed by Tukey's HSD test $(P=0.05)$ for mean separation. 


\section{Entomopathogen inhibition assay}

The entomopathogens $P$. larvae and $S$. marcescens were grown with shaking in TSB broth at $27^{\circ} \mathrm{C}$ for 4 days. Four different treatments, each with 4 replicates, were established: (i) control treatment; $6 \mathrm{~mL}$ of PDK broth added to $3 \mathrm{~g}$ of pollen. (ii) Pathogen treatment; pathogen cultures were diluted with sterile water to $10^{5} \mathrm{cfu} / \mathrm{mL}$ and $3 \mathrm{~mL}$ was introduced into a Petri dish containing $3 \mathrm{~mL}$ of PDK broth and $3 \mathrm{~g}$ of pollen. (iii) Pathogen with SP6C4 treatment; $3 \mathrm{~mL}$ of diluted pathogen and $3 \mathrm{~mL}$ of SP6C4 $\left(10^{6} \mathrm{cfu} / \mathrm{mL}\right)$ were mixed with $3 \mathrm{~g}$ of pollen in a Petri dish. (iv) Probiotic treatment; $3 \mathrm{~mL}$ of SP6C4 was mixed with $3 \mathrm{~mL}$ of PDK broth and $3 \mathrm{~g}$ of pollen in a Petri dish. Bumble bees (Bombus impatiens) usually consume pollen as principal food and survive effectively in small cages $^{45}$. Seven bumble bees were released into each plastic cage, the feeding mixtures were placed in the middle of the cages, and the numbers of dead bumble bees were counted every 24 hours for 5 days. Entomopathogen inhibition tests were compared using one-way ANOVA (P value $<0.05)$.

\section{Mutagenesis of SP6C4 with CRISPR/Cas9}

SP6C4 genomic DNA $(1 \mu \mathrm{g})$ and gene-specific primers were used to amplify the left arm (LA) and right arm (RA) regions for each target gene to be mutated (Supplementary Table 16). For each gene, (i) each LA and RA region was amplified by PCR; (ii) the LA and RA regions were linked by PCR; and (iii) the target homologue regions including LA and RA were amplified. PCR was performed in a MJ Research PTC-200 thermal cycler (Bio-Rad, USA). The amplicons were loaded onto a 1\% agarose gel and eluted in $30 \mu \mathrm{L}$ of EB buffer (Expin ${ }^{\mathrm{TM}}$ GelSV kit, GeneAll Biotechnology, Korea). A-tailing was performed with $100 \mathrm{mM}$ of dATP (NEB, Germany) at $70^{\circ} \mathrm{C}$ for $30 \mathrm{~min}$ and 
the solution was purified with 5 volumes GB buffer (Expin ${ }^{\mathrm{TM}}$ GelSV kit, GeneAll Biotechnology, Korea) and eluted in $20 \mu \mathrm{L}$. The purified molecule was ligated to a pGEM-T easy vector (Promega, USA) with T4 ligase (Promega, USA) by incubation at $16^{\circ} \mathrm{C}$ overnight and then transformed into E. coli DH5 $\alpha$. Transformants were detected by blue/white colony selection on LB medium (Luria broth $30 \mathrm{~g} / \mathrm{L}$ and agar $20 \mathrm{~g} / \mathrm{L}$ ) with ampicillin $(100 \mu \mathrm{g} / \mathrm{mL})$ and X-gal $(40 \mu \mathrm{g} / \mathrm{mL})$. Plasmids in white colonies were isolated with a Dokdo Mini-prep Kit (ELPIS-Biotech, Korea). Next, the vector and pCRISPomyces-gRNA ${ }^{46}$ were cut by $X b a \mathrm{I}$ (NEB, Germany), eluted in $30 \mu \mathrm{L}$ EB buffer, and a 3:1 ratio ligation was performed with 400,000 units (400 units/ $\mu \mathrm{L}$ ) of T4-ligase (NEB, Germany). The gRNA was cloned into pBHA (2002 bp), the pCRISPomyces-2 was cut with BbsI, and the two fragments were ligated with T4 ligase and ligated again with the gRNA. The resulting plasmid was transformed into E. coli ET12567 containing pUZ8002 $2^{47}$, and transformants were recovered on LB agar containing kanamycin $(30 \mu \mathrm{g} / \mathrm{mL})$, chloramphenicol $(25 \mu \mathrm{g} / \mathrm{mL})$ and apramycin $(50 \mu \mathrm{g} / \mathrm{mL})$. For seed cultures (E. coli ET12567/pUZ8002), single colonies were inoculated in LB broth containing the three antibiotics, transferred to $10 \mathrm{~mL}$ of $\mathrm{LB}$ broth containing the antibiotics, and incubated at $37^{\circ} \mathrm{C}$ for 9 hours with shaking at $150 \mathrm{rpm}$. The cultured cells were centrifuged (1,914 x g for $15 \mathrm{~min})$, gently washed twice in $10 \mathrm{~mL} \mathrm{LB}$ broth followed by centrifugation, and suspended in $500 \mu \mathrm{L}$ of LB broth. In a separate Eppendorf tube, 500 $\mu \mathrm{L}$ of $2 \mathrm{XYT}$ was heated to $50^{\circ} \mathrm{C}$ for $10 \mathrm{~min}$ and mixed with $10 \mu \mathrm{L}$ of a spore stock of SP6C4 $\left(10^{9} \mathrm{cfu} / \mathrm{mL}\right)$ in $20 \%$ glycerol. The washed E. coli cells were added to the SP6C4 spore stock, mixed by pipette, and spread on MS agar. Apramycin $(50 \mu \mathrm{g} / \mathrm{mL})$ and nalidixic acid $(25 \mu \mathrm{g} / \mathrm{mL})$ were overlaid on the plates $16 \mathrm{hr}$ later and after 7 days, colonies were transferred twice onto MS agar containing apramycin $(50 \mu \mathrm{g} / \mathrm{mL})$. Finally, each 
mutant was confirmed by PCR. All mutagenized strains and plasmids are listed in Supplementary Table 17.

\section{Statistical analyses}

All data except for sequence analyses were analyzed using SIGMA PLOT ver. 11.0 (System Software INC., Richmond, CA, USA). ANOVA was used to demonstrate differences among mean values and graphs were visualized by ggplots version 3.0.1 and ggplot2 version 2.1.0 (R package).

\section{Data availability}

Pyrosequencing data for flower samples have been deposited in the GenBank under SAR accession number SRP150491. All other data accession numbers are available in Supplementary Table 13.

\section{Acknowledgments}

We thank D. Schlatter of the USDA-ARS for critical comments on bioinformatics analyses, H-J, Hong of Oxford Brooks University for providing advice on Streptomyces molecular tools and comments on the manuscript. This research was supported by the Next-Generation BioGreen 21 Program (PJ013250).

\section{Author Contributions}

D.K, D.W, L.T and Y.K designed and developed the experiments. D.K, G.C and Y.K 
performed pyrosequencing analyses. D.K, G.C, T.P and Y.K conducted genome, bioinformatics and statistical analyses. D.K and Y.K carried out qRT-PCR and confocal microscope work. C.J and Y.K performed all the greenhouse work. D.K, D.W, L.T and Y.K wrote the manuscript.

\section{Competing interests}

The authors declare no competing interests.

\section{References}

1. Sánchez-Cañizares, C. et al. Understanding the holobiont: the interdependence of plants and their microbiome. Curr. Opin. Microbiol. 38, 188-196 (2017).

2. Vorholt, J.A. Microbial life in the phyllosphere. Nat. Rev. Microbiol. 10, 828-430 (2012).

3. Philippot, L. et al. Going back to the roots: the microbial ecology of the rhizosphere. Nat. Rev. Microbiol. 11, 789-799 (2013).

4. Pieterse, C.M.J. et al. The soil-borne supremacy. Trends Plant Sci. 21, 171-173 (2016).

5. Parray, J.A. et al. Current perspectives on plant growth-promoting rhizobacteria. $J$. Plant Growth Regul. 35, 877-902 (2016).

6. Thomashow, L.S. et al. The soil-borne legacy in the age of the holobiont. Microb. Biotechnol. doi.org/10.1111/1751-7915.13325 (2019). 
7. Bakker, P.A.H.M. et al. The soil-borne legacy. Cell 172, 1178-1180 (2018).

8. Faure, D. et al. Holobiont: a conceptural framework to explore the eco-evolutionary and functional implications of host-microbiota interactions in all ecosystems. New Phytol. 218, 131-1324 (2018).

9. Vandenkoornhuyse, P. et al. The importance of the microbiome of the plant holobiont. New Phytol. 206, 1196-1206 (2015).

10. Guerrero, R. et al. Symbiogenesis: the holobiont as a unit of evolution. Int. Microbiol. 16, 133-143 (2013).

11. Haas, D. \& Keel, C. Regulation of antibiotic production in root-colonizing Pseudomonas spp. and relevance for biological control of plant disease. Ann Rev Phytopathol. 41, 117-153 (2003).

12. Menendez, E. \& Garcia-Fraile, P. Plant probiotic bacteria: solutions to feed the world. AIMS Microbiol. 3, 502-524 (2017).

13. Levy, A. et al. Elucidating gene functions in the plant microbiome. Cell, Host Microbe 24, 475-485 (2018).

14. Lebeis, S.L. et al. Plant microbiome. salicylic acid modulates colonization of the root microbiome by specific bacterial taxa. Science, 349, 860-864 (2015).

15. Castrillo, G. et al. Root microbiota drive direct integration of phosphate stress and immunity. Nature 543, 513 (2017).

16. Aleklett, A. et al. The microbial ecology of flowers: an emerging frontier in phyllosphere research. Botany 92, 253-266 (2014). 
17. Jacoby, R. et al. The role of soil microorganisms in plant mineral nutrition-current knowledge and future directions. Front. Plant Sci. 8, 1617 (2017).

18. Berendson, R.L. et al. Disease-induced assemblage of a plant-beneficial bacterial consortium. ISME J. 12, 1496-1507 (2018).

19. Cha, J. et al. Microbial and biochemical basis of Fusarium wilt-suppressive soil. ISME $J$ 10, 119-129 (2016).

20. Mendes, R. et al. Deciphering the rhizosphere microbiome for disease-suppressive bacteria. Science, 332, 1097-1100 (2011).

21. Durán, P. et al. Microbial interkingdom interactions in roots promote Arabidopsis survival. Cell 175, 973-983 (2018).

22. Leach, J.E. et al. Communication in the Phytobiome. Cell, 169, 587-596 (2017).

23. Rong, X. \& Huang. Y. Taxonomic evaluation of the Streptomyces griseus clade using multilocus sequence analysis and DNA-DNA hybridization, with proposal to combine 29 species and three subspecies as 11 genomic species. Int. J. Syst. Evol. Microbiol. 60, 696-703 (2010).

24. Konstantinidis, K.T. \& Tiedje, J.M. Towards a genome-based taxonomy for prokaryotes. J. Bacteriol. 187, 6258-6264 (2005).

25. Kim, D. et al. Function and distribution of a lantipeptide in strawberry Fusarium wilt disease-suppressive soils. Mol. Plant Microbes Inter. 32, 306-312 (2019).

26. Medema, M.H. et al. antiSMASH: Rapid identification, annotation and analysis of secondary metabolite biosynthesis gene clusters in bacterial and fungal genome 
sequences. Nucleic Acids Res. 39, 339-346 (2011).

27. Hartmann, A. et al. Lorenz Hiltner, a pioneer in rhizosphere microbial ecology and soil bacteriology research. Plant Soil 312, 7-14 (2008).

28. Mitter, B. et al. Plant-microbe partnerships in 2020. Microb. Biotechnol. 9, 635-640 (2016).

29. Hassani, M.A. et al. Microbial interactions within the plant holobiont. Microbiom 6, 58 (2018).

30. Rosenberg, E. \& Zilber-Rosenberg, I. Microbes drive evolution of animals and plants: the hologenome concept. MBio 7, e01395-15 (2016).

31. Edwards, J. et al. Structure, variation, and assembly of the root-associated microbiomes of rice. Proc. Natl. Acad. Sci. USA 112, E911-E920 (2015).

32. Chi, F. et al. Ascending migration of endophytic rhizobia, from root to leaves, inside rice plants and assessment of benefit to rice growth physiology. Appl. Environ. Microbiol. 71, 7271-7278 (2005).

33. Frank, A.C. et al. Transmission of bacterial endophytes. Microogranism, 5, 70 (2017).

34. Wei, N. \& Ashman, T.-L. The effects of host species and sexual dimorphism differ among root, leaf and flower microbiomes of wild strawberries in situ. Sci. Reports $\mathbf{8}$, 5195 (2018).

35. Commoner, B. The closing circle: nature, man \& technology. Alfred A. Knopf. New York. USA. (1971). 


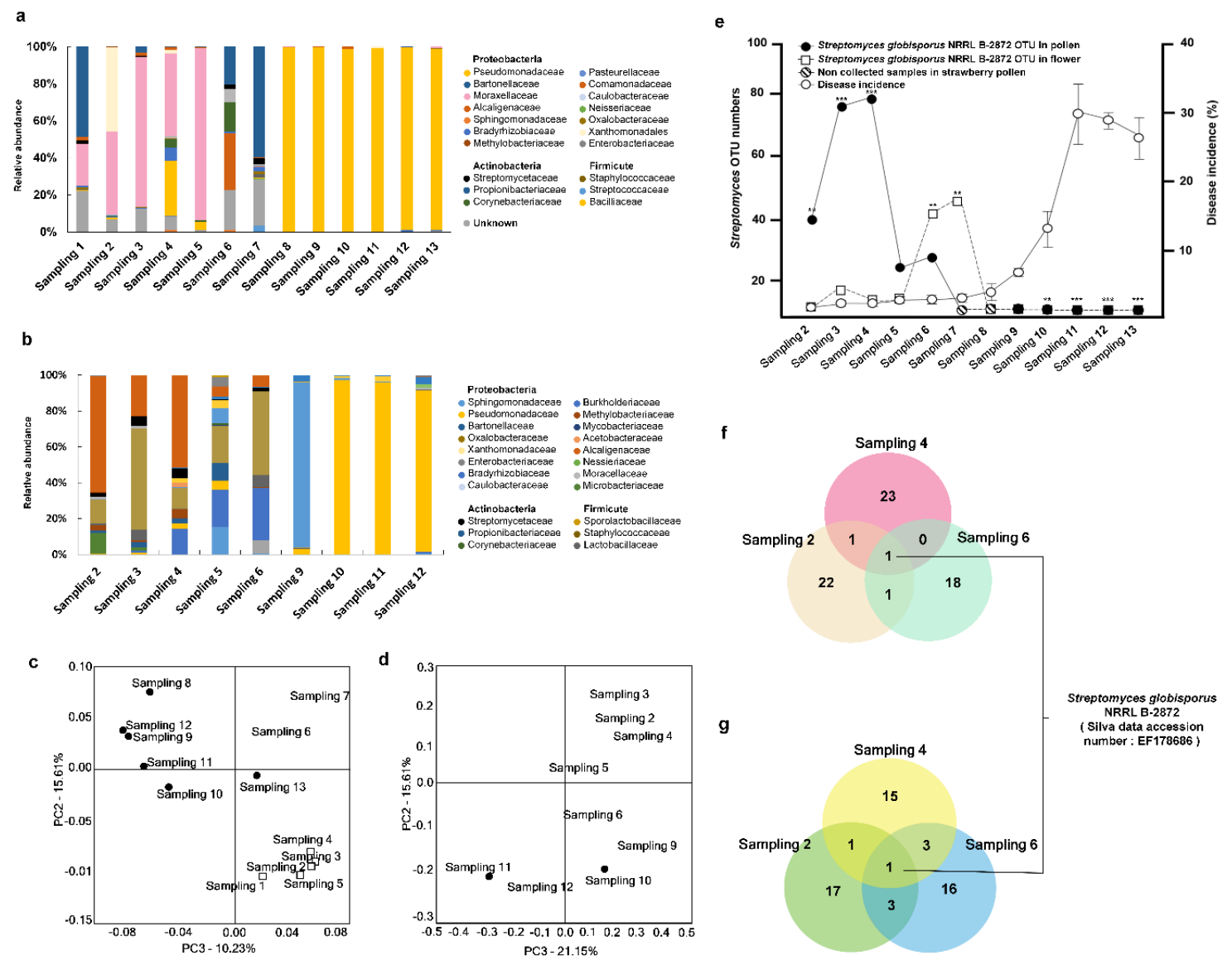

Fig. 1| Microbial diversity of strawberry flowers and pollen. a, Pyrosequencing of microbes in strawberry flowers $(n=9,13$ independent experiments) and $\mathbf{b}$, pollen $(n=2$, 9 independent experiments). Taxonomic assignment was conducted at the family level with the Silva database (http://www.arb-silva.de/) and a cutoff of $97 \%$ similarity. $\mathbf{c}$ and d, Principal coordinate analysis of microbial diversity is shown by comparing the PC values for each order, and then the value was vectorized to show the spatial position. White squares designate the high diversity group (HD) and the black circles, the low diversity group (LD). d, Gray mold incidence over a growing season as related to Streptomyces OTU read numbers. Gray mold incidence, bars represent standard error of 
nine blocks, each block contains 100 plants. Star (*) indicates statistically significant differences between disease incidence and OTU numbers of Streptomyces globisporus NRRL B-2872, which is identical to SP6C4 and SF7B6 by T-test (P value $<0.05)$. f, Venn diagram of common OTUs in HD samples during low gray mold incidence. 

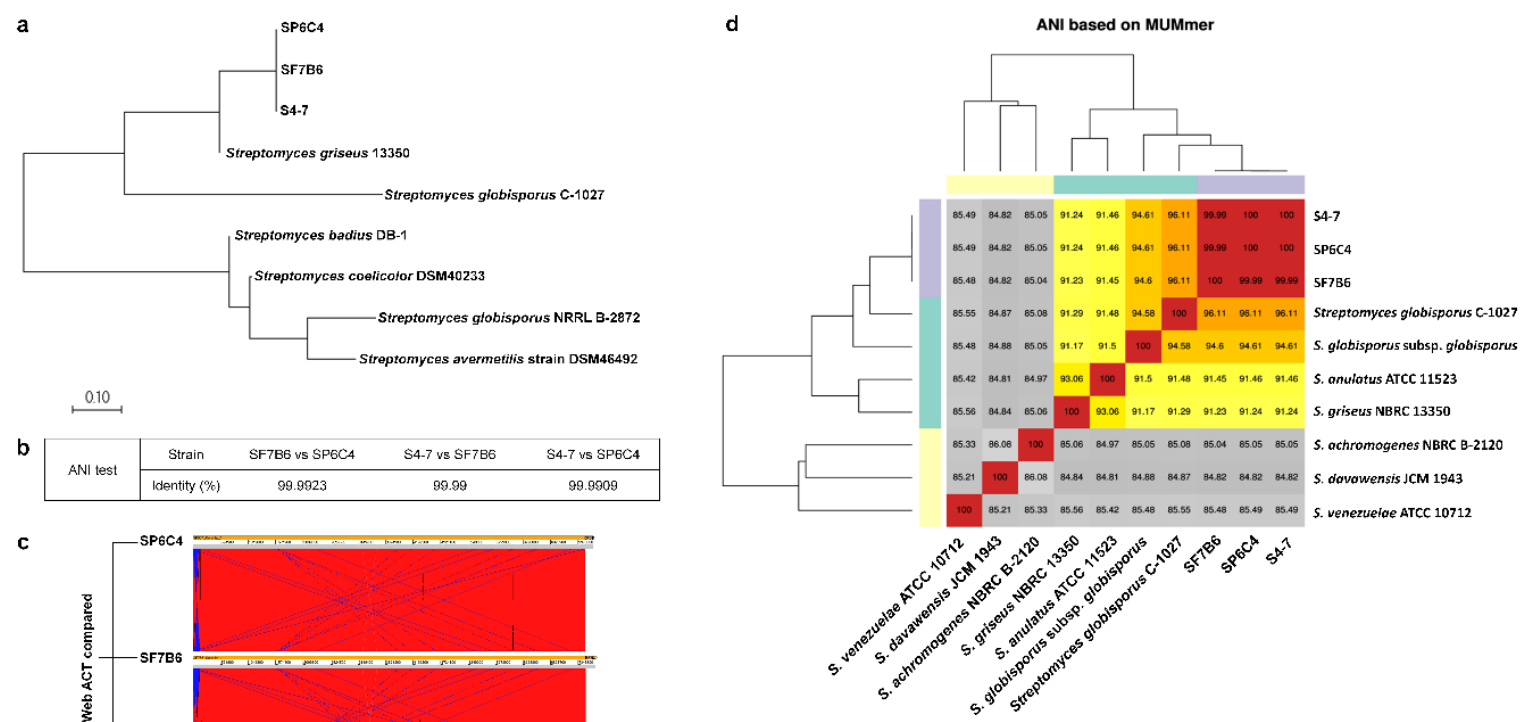

Fig. 2| Identification of strains SP6C4, SF7B6 and S4-7 at the genome level. a, Phylogenetic tree of strains SP6C4, SF7B6 and S4-7 based on 16S rRNA and housekeeping genes ( $g y r B$ and $\operatorname{rec} A$ ). Sequences were compared by multiple alignment analyses using the UPGMA method of MEGA 7. b, Average nucleotide identity (ANI) of the strains. c, Web ACT (http://www.webact.org/WebACT), blast parameters of nucleotide mismatch penalty -1 ; gap opening penalty 1 ; gap extension penalty 2 . d, ANI genome alignment threshold was raised to $94 \%$. 
a

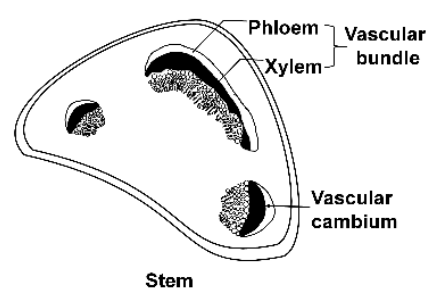

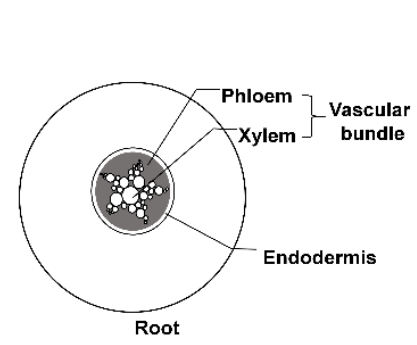

b
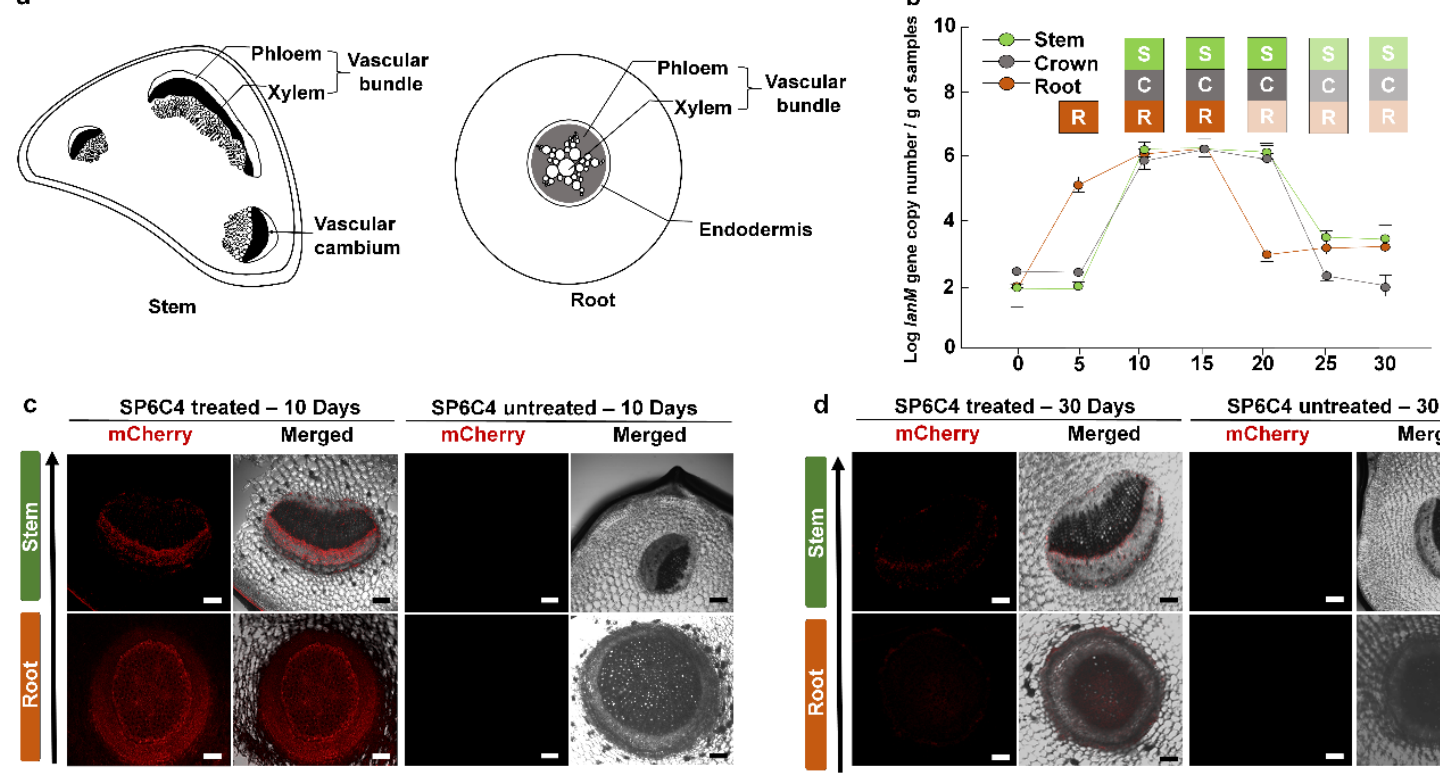

SP6C4 untreated - 10 Days

d $\frac{\text { SP6C4 treated }-30 \text { Days }}{\text { mCherry }} \frac{\text { SP6C4 untreated }-30 \text { Days }}{\text { Merged }}$
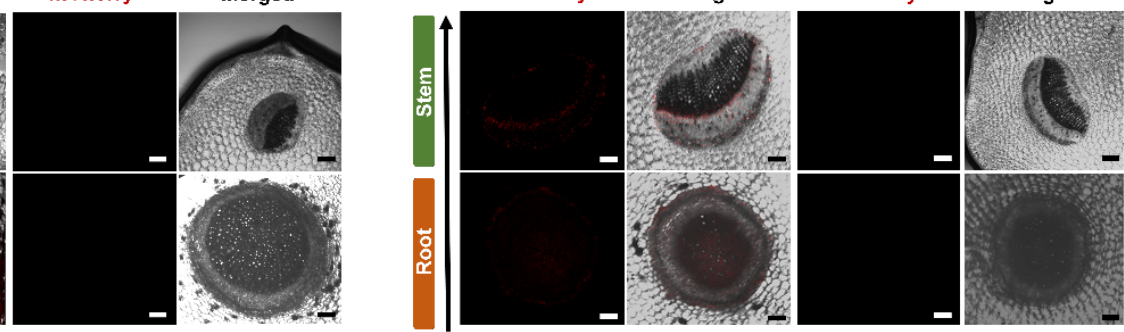

f $\frac{\text { Treated }-5 \text { Days }}{\text { mCherry Expansion }} \frac{\text { Untreated }-5 \text { Days }}{\text { mCherry Merged }}$
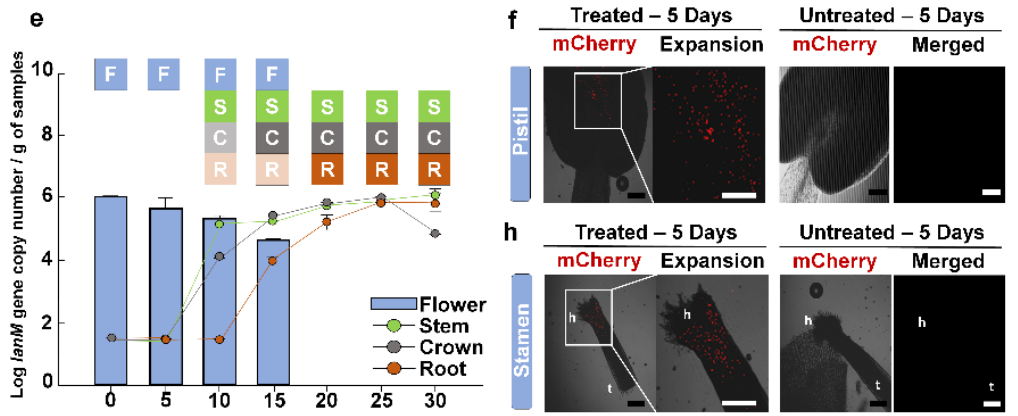

Treated -15 Days

Untreated - 15 Days mCherry Expansion mCherry Merged

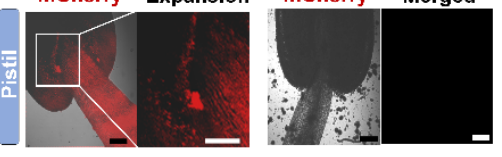

Untreated - 5 Days i Treated - 15 Days Untreated - 15 Days

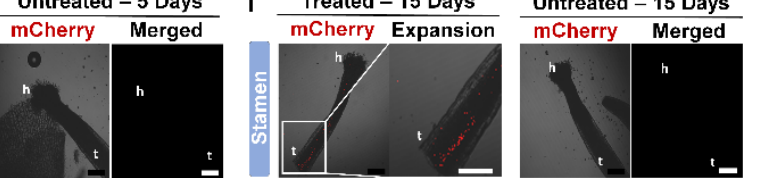

j
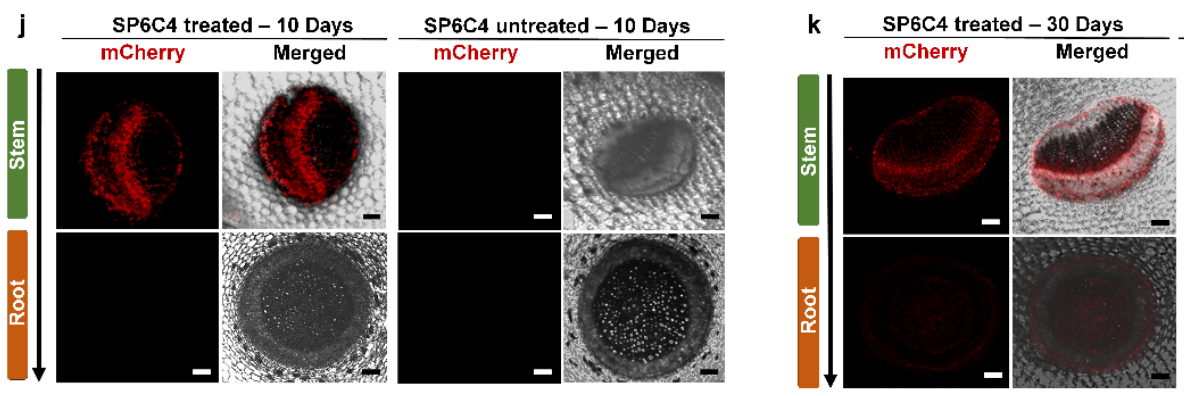

SP6C4 untreated -30 Days
mCherry $\quad$ Merged
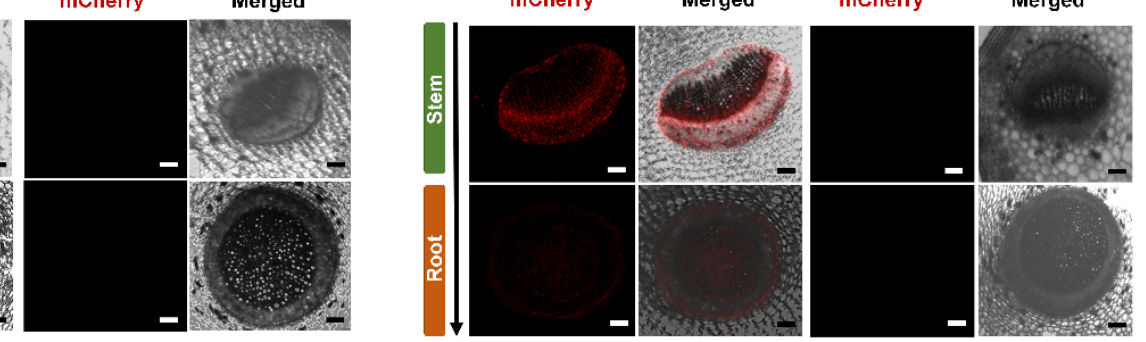

\section{Fig. 3| Translocation of the Streptomyces probiotic strain SP6C4 from below to above}

ground and vice versa. a, Illustration of the cross section of a strawberry stem and root.

b, S. globisporus SP6C4 was introduced onto the root surface in a suspension with $0.1 \%$ methylcellulose. Endophytic S. globisporus SP6C4 was detected with a lanM specific primer using qPCR SYBR Green ${ }^{\circledR}$ TOYOBO master mix. Bars represent $\pm \mathrm{SE}(n=3,3$ independent experiments). c, Confocal microscopy of plant samples sectioned at 10 days. 
d, 30 days after inoculation. Fluorescence of strain SP6C4-mCherry (530-560 nm detection channels) showing translocation from the rhizosphere to phyllosphere. e, Strain SP6C4 introduced on the flower and detected by lanM-specific qPCR. Movement of the strain from above ground to below ground plant parts. Bars represent $\pm \mathrm{SE}$ (flower: $n=5$, 3 independent experiments; root and stem: $n=3,3$ independent experiments; crown: $n=$ 3, 3 independent experiments). f, SP6C4-mCherry on the pistil at 5 days (mCherry channel scale bar, $100 \mu \mathrm{m}), 15$ days samples $(\mathbf{g})$. h, SP6C4-mCherry on stamen at 5 days (i) and 15 days Stem and root at 15 days (j). k, 30 days after inoculation. The plant was maintained in a growth chamber with $16 \mathrm{~h}$ light, $28^{\circ} \mathrm{C}, 45 \%$ relative humidity, and $8 \mathrm{~h}$ dark, $24^{\circ} \mathrm{C}, 45 \%$ relative humidity. 

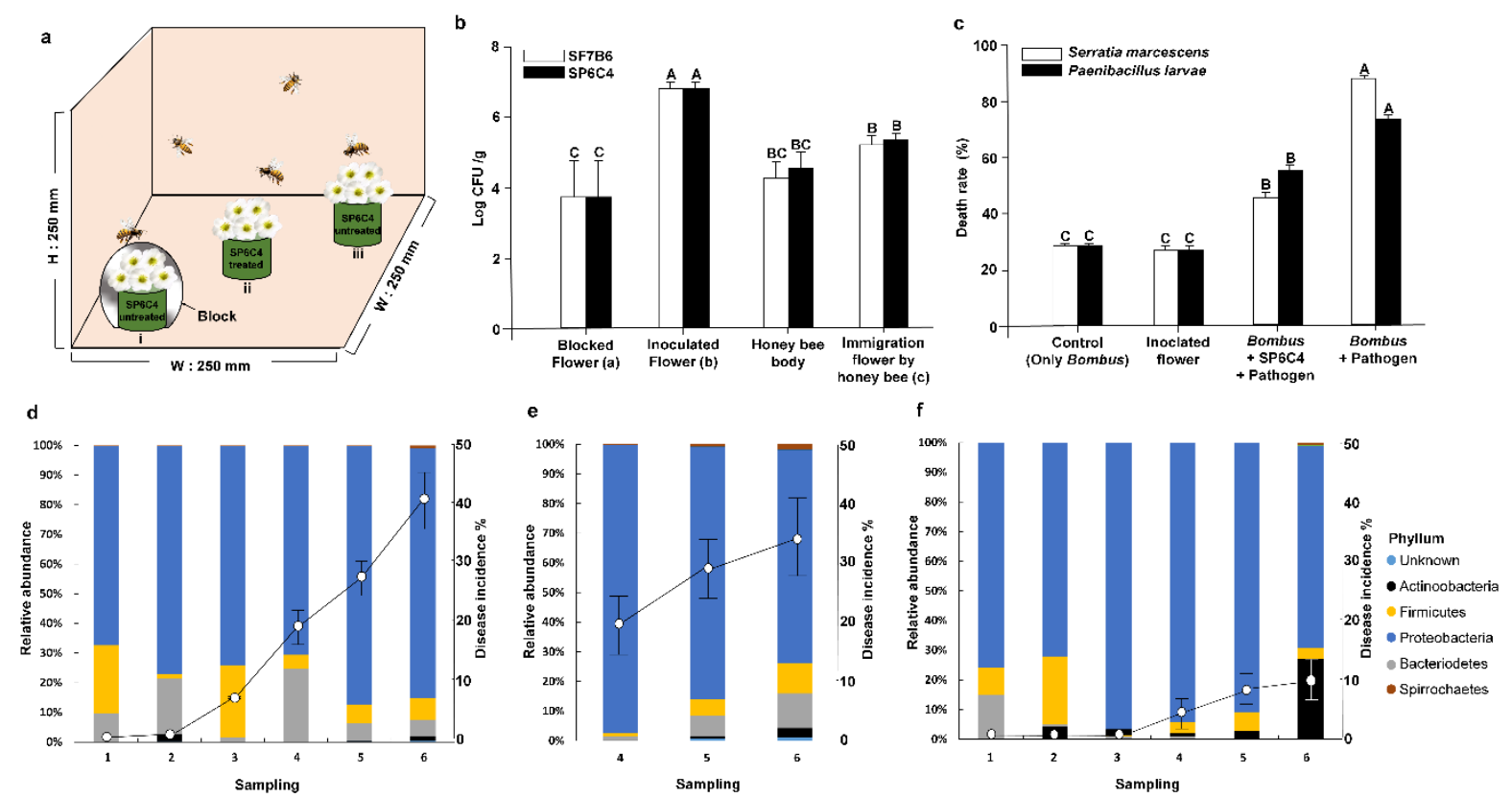

Fig. 4| S. globisporus SP6C4 reduced incidence of gray mold and insect mortality. a,

Illustration of honeybee transport of the probiotic from plant to plant. (i): honeybee access blocked by a cap, (ii): flower stamens and carpels inoculated with a suspension (100 $\mu \mathrm{L})$ of SP6C4 $\left(10^{6} \mathrm{cfu} / \mathrm{mL}\right)$, (iii): non-treated flower $(n=5$ independent replications). b, Population densities of SF7B6 and SP6C4 on flowers and honeybee bodies. Surface bacteria were detached by sonication for 30 mins at $35 \mathrm{kHz}$. Streptomyces strain was isolated on PDK media amended with hygromycin B $(80 \mu \mathrm{g} / \mathrm{mL})$. Bars with different letters are significantly different according to Tukey's $\operatorname{HSD}(P=0.05, n=7)$. c, Mortality of Bombus impatiens. Entomopathogens $\left(10^{5} \mathrm{cfu} / \mathrm{mL}\right)$ were added with or without SP6C4 $\left(10^{6} \mathrm{cfu} / \mathrm{mL}\right)$ to pollen. Data are means $\pm \mathrm{SE}$ and bars with different letters are significantly different according to Tukey's HSD $(P=0.05)$. $S$. globisporus SP6C4 was cultured in PDK broth at $28^{\circ} \mathrm{C}$ for 7 days, washed, mixed with PEG 8000 to give final concentrations of $10^{7} \mathrm{cfu} / \mathrm{mL}$ and $12.5 \%$ PEG, and then introduced into the greenhouse via a honeybee delivery system. Gray mold incidence (line) and the microbial community (bars) were 
monitored. Taxonomy data were converted to Newick format on R (version 3.4.0) script. The converted taxonomic data were visualized with ggtree (version 3.4.11) and ggplot2 (version 2.2.1) packages. d, SP6C4 untreated control greenhouse, honey bee access blocked by net in SP6C4 treated greenhouse (e), strain SP6C4-treated greenhouse (f). 